Original Research Paper

\title{
Kemudahan Penggunaan Augmented Reality sebagai Alat Bantu Pembelajaran Online bagi Meningkatkan Kinerja dan Prestasi Siswa Dalam Seni Ukiran Kayu
}

\author{
Salini Krishna Pillai ${ }^{1}$, Nur Iksan ${ }^{2}$, Harleny Abd Arif ${ }^{3}$, Ismail Yusuf Panessai ${ }^{1}$, Azmi \\ Shawkat Abdulbaqie ${ }^{4}$, Achmad Yani ${ }^{5}$, Ismail ${ }^{6}$ \\ ${ }^{1}$ Department of Computing, Faculty of Art, Computing \& Industry Creative, Universiti \\ Pendidikan Sultan Idris, Malaysia. \\ ${ }^{2}$ Fakultas Teknik, Universitas Riau Kepulauan (UNRIKA). Batam, Indonesia. \\ ${ }^{3}$ Department of Art \& Design, Faculty of FSKIK, UPSI, Malaysia. \\ ${ }^{4}$ College of Computer Science \& Information Technology, University of Anbar. Iraq. \\ ${ }^{5}$ Universiti Sains Malaysia. Penang, Malaysia. \\ ${ }^{6}$ Program Studi Teknik Informatika, Fakultas Teknik. UIS. Batam, Indonesia.
}

Article History

Received:

01.08.2021

Revised:

13.08.2021

Accepted:

15.08 .2021

*Corresponding Author:

Ismail Yusuf Panessai

Email:

ismailyusuf@fskik.upsi.edu.my

This is an open access article, licensed under: $\mathrm{CC}-\mathrm{BY}-\mathrm{SA}$
Abstrak: Krisis global pasca merebaknya epidemi Covid-19 berdampak pada proses belajar mengajar (PdP). Masalah utama pdP selama epidemi Covid-19 adalah keterbatasan dalam melakukan kegiatan tatap muka di dalam kelas. Oleh karena itu, diperlukan bantuan pembelajaran agar PdP dapat berjalan optimal meskipun tidak ada interaksi tatap muka antara guru dan siswa. Penelitian ini menyoroti penerapan Augmented Reality untuk mendukung pembelajaran jarak jauh dalam situasi epidemi Covid-19, khususnya dalam topik seni ukiran kayu. Aplikasi selular AR Wood Carving Art menggunakan model desain ADDIE. Aplikasi seluler AR Wood Carving Art dievaluasi berdasarkan kegunaannya (ease of use). Berdasarkan hasil penelitian, responden menyetujui bahwa aplikasi selular AR Wood Craving Art berguna dan aplikasi menghemat waktu ketika pengguna menggunakannya sehingga aplikasi selular AR Wood Craving Art efektif digunakan dalam pembelajaran yang membuat pengguna lebih produktif, kreatif, dan inovatif.

Kata Kunci: Augmented Reality, Kemudahan Penggunaan, Pengajaran dan Pembelajaran.

Ease of Use of Augmented Reality as an Online Learning Tool to Improve Student Performance and Achievement in Wood Carving Art

Abstract: The global crisis following the outbreak of the Covid-19 epidemic has had an impact on the teaching and learning process (PdP). The main problem with PdP during the Covid-19 epidemic was the limitation in conducting face-to-face activities in the classroom. Therefore, a learning aid is needed to enable PdP to run optimally even though there is no face-to-face interaction between teachers and students. This research highlights the application of Augmented Reality to support distance learning in the Covid19 epidemic situation, specializing in Wood Carving Art for the subject of Visual Arts. The AR Wood Carving Art mobile application uses the ADDIE design model. The AR Wood Carving Art mobile application is evaluated based on its ease of use. Based on the result, respondents agree that the AR Wood Craving Art mobile application is useful and the application saves time when users use it, therefore the AR Wood Craving Art mobile application is effectively used in learning which makes users more productive, creative, and innovative.

Keywords: Augmented Reality, Ease of Use, Teaching and Learning. 


\section{Pendahuluan}

Aplikasi selular Augmented Reality (AR) dalam pendidikan meningkat pesat seiring dengan kelayakan penggunaan mobile AR yang meningkat karena kemajuan teknologi mobile [1] [2] [3]. Augmented Reality lebih mudah diakses oleh generasi Z. Seperti yang diketahui, siswa generasi Z lebih suka menggunakan teknologi daripada diskusi tatap muka terutama dalam pendidikan. Untuk beradaptasi dengan tren saat ini guru sebagai pemancar pengetahuan perlu meningkatkan pengetahuan mereka dalam teknologi dan menghasilkan konten kreatif. Penggunaan teknologi dalam proses pembelajaran tidak dapat dipisahkan tetapi perlu digunakan dengan bijak agar tidak membahayakan [4] [5]. Mengikuti perkembangan pendidikan di dunia harus menjadi tujuan pendidikan di dunia modern ini, dan tidak bergantung kepada pengetahuan dan sistem statis [6] [7] [8]. Demikian juga siswa diharapkan menggunakan teknologi untuk menunjang kesuksesan mereka di bidang akademik [9].

Sebagian besar sekolah telah dihadapkan dengan pergeseran tiba-tiba dan tidak siap ke pengajaran secara daring untuk menanggapi kebutuhan dan melanjutkan kegiatan belajar mengajar ketika langkah-langkah jarak sosial diterapkan. Hal ini terjadi karena kita tidak menyadari covid-19 dan tidak bisa mempredeksi waktu yang diperlukan untuk kembali kepada keadaan normal (keadaan transisi). Transisi dapat diurai menjadi beberapa dimensi yang saling terhubung yang berdampak pada kelayakan dan kualitas pembelajaran jarak jauh yang disediakan [10] [11].

Siswa perlu memiliki akses teknologi sebagai indikator utama kesiapan belajar secara daring. Karena siswa juga belajar secara mandiri, instruktur mungkin juga membutuhkan lebih banyak waktu untuk merancang pengiriman konten mereka secara efektif karena siswa pasti akan menghadapi kesulitan teknis dan adaptasi.

Guru sebagai perantara dalam menyampaikan pengajaran dan siswa sebagai penerima konten pembelajaran perlu memiliki pergeseran paradigma untuk menerima skenario baru agar melek teknologi digital. Oleh karena itu, untuk beradaptasi dengan lingkungan baru maka memberikan konten terstruktur secara tertulis itu tidak praktis. Dengan kata lain, salah satu alat presentasi yang sesuai untuk menyampaikan sebuah silabus adalah 3 Dimensi. Kemapuan memhami 3D membantu siswa untuk memvisualisasikan objek secara realistis dan meningkatkan keterampilan imajiner.

Selain itu, krisis global pasca merebaknya epidemi Covid-19 mengingatkan kesiapan proses belajar mengajar (PdP) melalui virtual gateway. Keterbatasan melakukan kegiatan di luar kelas bukan menjadi alasan karena guru dapat membawa siswa mengunjungi lokasi tertentu selain membuat eksplorasi melihat lebih dekat mata pelajaran belajar melalui aplikasi AR interaktif yang dikembangkan. Dengan mengintegrasikan AR ke dalam mata pelajaran seni ukir maka alat bantu pembelajaran dapat digunakan oleh guru atau oleh siswa belajar sendiri untuk pemahaman dan pengetahuan yang lebih baik.

\section{Literatur}

Sesi ini menjelaskan literatur yang relevan dengan penelitian, yang mencakup jenis-jenis Augmented Reality, alat yang digunakan untuk mengembangkan Augmented Reality, Augmented Reality dalam pendidikan, seni ukir kayu, dan model ADDIE.

\subsection{Jenis Augmented Reality}

AR telah menarik perhatian orang-orang dengan mengekspos kemampuan untuk mengintegrasikan konten digital secara halus dengan lingkungan dunia nyata [12]. Konten digital ini meningkatkan pemahaman dan imajinasi suatu objek [13]. Augmented Reality membantu memvisualisasikan gambar dalam berbagai bentuk, termasuk animasi dan grafik gerakan, suara, dan tombol.

Empat jenis AR adalah Augmented Reality Berbasis Penanda, Augmented Reality tanpa Penanda, Augmented Reality Proyeksi, dan Augmented Reality Berbasis Superimposisi [14].

1. Augmented Reality Berbasis Penanda yang juga dikenal sebagai pengenalan gambar akan mendeteksi objek di depan kamera dan memantulkan objek di layar. Pendekatan masingmasing fleksibel yang memungkinkan tampilan dari sudut dan arah yang berbeda [15] [16].

2. Marker Less Augmented Reality adalah salah satu teknik termudah dan sedang tren. Penggunaan jenis Marker Less Augmented Reality adalah pada pendeteksi lokasi [17]. Hampir semua pengguna smartphone pernah menggunakannya.

3. Augmented Reality berbasis proyeksi adalah jenis AR yang mencerminkan cahaya yang memantul di permukaan. Tidak diperlukan perangkat tertentu kecuali proyektor [18] [19].

4. Augmented Reality Berbasis Superimposisi adalah ejnis AR yang menggantikan gambar 
dengan objek yang realistis. Pendekatan ini melibatkan imajinasi dan kreativitas [20] [21].

\subsection{Alat Pengembangan Augmented Reality}

Alat dan platform pengembangan AR banyak tersedia saat ini. Salah satu Software Development Kit (SDK) yang baik adalah Vuforia. Vuforia menyediakan kerangka kerja yang sangat baik untuk pengembangan AR [6] [7] [14]. Fungsionalitas dominan muncul dengan rekognisi teks, dan 2-Dimensi dan 3-Dimensi. Selain itu, pemindai barcode berisi data dan bertindak sebagai penanda untuk mendeteksi objek. Fasilitas pemutaran video berdasarkan permintaan dan tombol virtual untuk perubahan permukaan menjadi layar sentuh. Data dapat disimpan di cloud atau penyimpanan di perangkat. Empat platform utama yang didukung adalah studio android, IOS, Universe Window Platform, dan pengembangan Unity.

SDK terkenal kedua yang membuat aplikasi berbasis Augmented Reality adalah Wikitude. Fungsi Wikitude sebelumnya memungkinkan pembuatan aplikasi untuk kacamata pintar dan informasi dapat disimpan di cloud atau di perangkat. Wikitude memiliki atribut khusus dalam menyediakan layanan berbasis lokasi seperti Google Maps, GPS, dan pembaruan lokasi langsung [6]. Wikitude memanfaatkan JAVASCRIPT API, NATIVE API, CORDOVA, Unity 3D untuk pengembangan. Selain itu, gunakan objek, pengenalan gambar, dan manipulasi objek virtual. Tiga platform utama yang didukung adalah studio android, IOS, pengembangan Microsoft Surface.

AR Kit dapat mengidentifikasi pengukuran lingkungan sekitar. Mendukung deteksi gambar 2Dimensi dan 3-Dimensi dan permukaan pelacakan untuk menempatkan objek [4] [5]. AR Kit mengkhususkan diri dalam membuat game Augmented Reality multipemain, deteksi pesawat horizontal yang mudah dideteksi, dan jalur wajah juga. Satu-satunya platform yang didukung AR Kit adalah aplikasi IOS 11plus dan biayanya gratis.

Empat Kit Pengembangan Perangkat Lunak teratas terakhir adalah MAXST. Fungsionalitas utama adalah melacak lingkungan dan memetakan lingkungan. Aktifkan untuk memindai kode batang dan respons cepat $(\mathrm{QR})$. Karakteristik Essential dapat melacak beberapa target sekaligus, mengurangi tugas yang memakan waktu dan menyelesaikan lebih awal dari yang diharapkan. MAXST juga menyediakan efek oklusi untuk melihat objek virtual layar secara nyata sepenuhnya. Empat platform utama yang didukung adalah studio android, IOS, Universe Window Platform, dan pengembangan Unity.

\subsection{Augmeneted Reality dalam Pendidikan}

Teknologi AR memungkinkan pengguna untuk mengalami fenomena ilmiah yang tidak mungkin terjadi di dunia nyata, seperti reaksi kimia tertentu, membuat materi pelajaran yang tidak dapat diakses oleh siswa [22]. Manipulasi objek virtual dan pengamatan fenomena yang sulit diamati di dunia nyata dapat difasilitasi melalui AR [1]. Seperti yang dikatakan, AR berkontribusi besar pada pendidikan. Dengan melihat keadaan sekarang, pandemi covid-19 mempengaruhi pendidikan dengan cara yang tidak terduga dan untuk mengatasi masalah yang dialami oleh seorang guru maka AR digunakan sebagai salah satu alat bantu pemancar pengetahuan [23].

D. Seni ukir kayu dalam pendidikan seni rupa

Tujuan pendidikan Seni Rupa adalah membentuk kepribadian generasi Malaysia yang melek budaya, memiliki nilai estetika tinggi, imajinatif, kritis, kreatif, inovatif, dan inventif. Isi kurikulum dapat membantu siswa meningkatkan rasa syukurnya kepada Tuhan, menghargai keindahan lingkungan, keindahan seni, dan warisan bangsa, serta dapat berkontribusi terhadap perkembangan diri, masyarakat, dan negara, sejalan dengan aspirasi Filsafat Pendidikan Nasional Malaysia [24]. Pendidikan seni rupa mengekspresikan kreativitas seni dalam bentuk ukiran. Pendidikan seni rupa adalah mata pelajaran wajib bagi siswa sekolah dasar Sementara itu bagi siswa menengah wajib mengambil dari Formulir 1 ke Formulir 3.

Dokumen Kurikulum dan Standar Penilaian (DSKP) berisi silabus Kurikulum Terpadu Sekolah Menengah (KBSM). Dokumen ini mencakup empat komponen utama yaitu Standar Konten, Standar Pembelajaran, Aktivitas yang Disarankan, dan Tingkat Penguasaan [24]. Sementara itu, standar pembelajaran berbasis kualitas pembelajaran dan tanda pemeriksaan evaluasi cukup besar. Kegiatan yang disarankan dan tingkat penguasaan adalah untuk meningkatkan keterampilan dan kekuatan siswa untuk hasil yang lebih baik [25].

Seni ukir kayu memiliki banyak contoh seperti garis, bunga, arsitektur, warna, ruang, dan [26]. Selain itu, seni memiliki kekuatan untuk mengekspresikan emosi dan ide dalam aspek yang menarik [27]. Persepsi belajar seni adalah mengembangkan pengetahuan dan kesadaran siswa dalam 
pendidikan seni rupa untuk mendorong mahasiswa untuk kreatif dan inovatif dalam bermusyrekan. Eksplorasi seni memungkinkan siswa untuk mengeksplorasi secara mendalam tentang seni dan warisannya. Singkatnya, mengeksplorasi Pendidikan Seni rupa secara intensif membantu siswa menjadi inovatif dan visioner [24].

\subsection{Model Desain Sistem Instruksional}

Model Desain Sistem Instruksional (ISD) khusus untuk courseware pendidikan [28]. Gambar 1 memperlihatkan diagram Model ADDIE.

Model ADDIE adalah contoh terbaik dari Model ISD. Nama ADDIE berasal dari nama tahapannya yaitu Analisis (Analyze), Perancangan (Design), Pengembangan (Development), Implementasi (Implementations), dan Evaluasi (Evaluations) [29] [30].

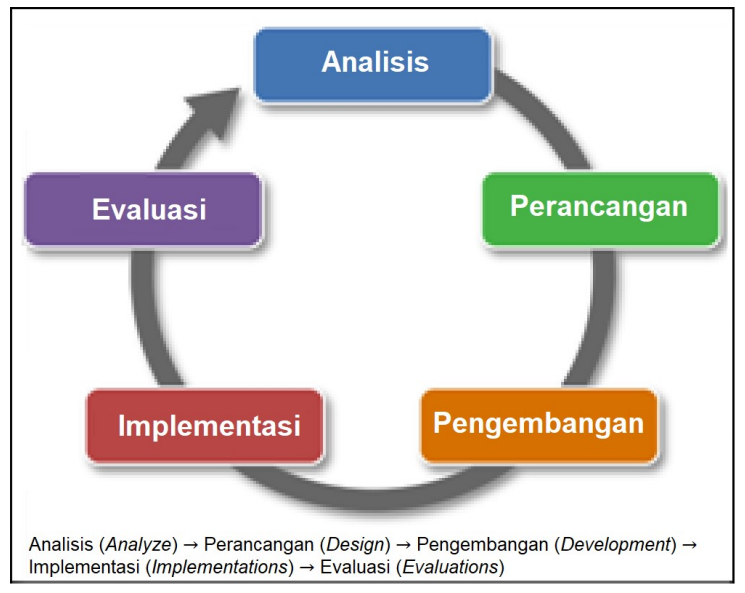

Gambar 1. Model ADDIE

\section{Metode Penelitian}

Sesi ini membahas metodologi yang dipilih untuk menyelesaikan penelitian dengan formula dan praktik yang sesuai. Metode penelitian mencakup spesifikasi perangkat keras dan perangkat lunak, serta instrumen penelitian yang digunakan untuk proses pengembangan.

Gambar 2 menunjukkan kerangka kerja penelitian yang digunakan.

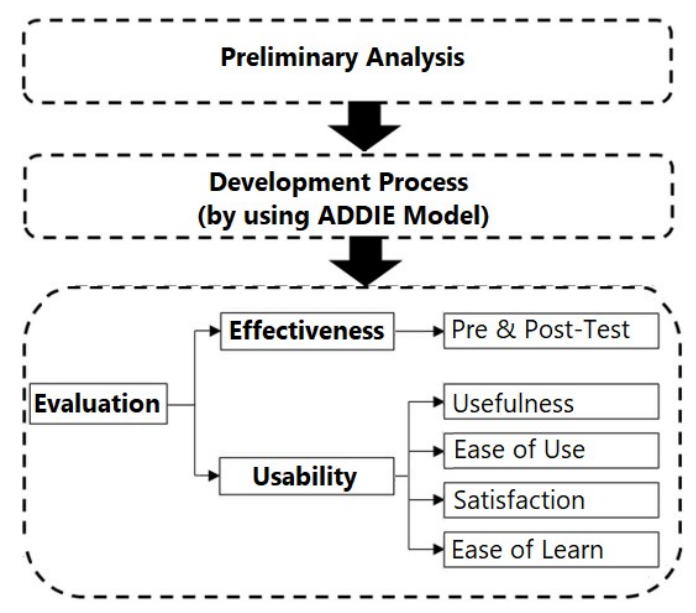

Gambar 2. Kerangka Kerja Penelitian 
Tahap pertama adalah analisis awal. Pada tahap ini, analisis didasarkan pada pembacaan dan analisis studi sebelumnya terkait integrasi teknologi berbasis komputer seperti courseware dan AR di bidang proses belajar mengajar. Fase 2 melibatkan proses pengembangan AR Wood Carving sebagai alat dengan menerapkan model ADDIE. Data yang dikumpulkan dari analisis digunakan untuk merancang dan membangun konten AR menggunakan platform yang ada.

Tahap akhir dalam pelaksanaan penelitian ini adalah evaluasi. Evaluasi yang dilakukan ada dua, yaitu effectiveness dan usability. Pengujian usability untuk mengetahui seberapa mudah sebuah produk bisa digunakan oleh pengguna tertentu untuk mencapai tujuan tertentu dengan efektif, efisien dan memperoleh kepuasan dalam konteks penggunaannya [31]. Untuk mengukur usability digunakan instrument yang disebut USE (Usefulness, Satisfaction, and Ease of Use). Bentuk kuesioner USE terdiri atas Usefulness, Ease of Use, Satisfaction dan Ease of Learning. Dalam penelitian ini, evaluasi usability dilakukan untuk mengetahui sejauh mana Aplikasi seluler AR Wood Carving Art dapat membantu meningkatkan kinerja dan prestasi siswa (usefulness).

\subsection{Perangkat Lunak}

Tiga perangkat lunak dasar yang digunakan dalam pengembangan aplikasi AR adalah Unity 3Dimensional, Vuforia SDK, dan Android Software Development Kit (SDK) [30] [32] [33]:

1. Unity 3D. Unity 3D adalah platform pengembangan real-time terbaik di dunia dengan ekosistem yang kuat yang dirancang untuk memungkinkan keberhasilan sistem. Unity mendukung berbagai platform seperti IOS, Android, Windows, dan Xbox One. Unity adalah bagian dari lingkungan pengembangan terpadu (IDE) di mana pengguna dapat menggunakan bahasa pemrograman yang mudah seperti $\mathrm{C}$ dan JavaScript. Dalam pembangunan aplikasi selular AR Wood Carving Art, Unity akan berguna untuk merancang dan membuat gambar seni 3 Dimensi untuk pada Wood Carving Art.

2. Vuforia SDK. Vuforia adalah Kit Pengembangan Perangkat Lunak Augmented Reality (SDK) untuk perangkat seluler yang cenderung membuat Aplikasi AR. Vuforia juga memungkinkan penyimpanan data, berfungsi sebagai database untuk aplikasi. Dalam pembangunan aplikasi selular AR Wood Carving Art, Vuforia memiliki fungsi seperti menelusuri gambar, memberikan sudut penyesuaian gambar yang berbeda, dan memungkinkan penciptaan objek dalam perspektif yang berbeda.

3. Android SDK. Android Software Development Kit memungkinkan pengembang untuk mengembangkan aplikasi dengan cepat dan mudah. Salah satu alat pengembangan terbaik untuk membangun aplikasi terdepan di pasar dan mempercepat kinerja. Contoh alat pengembangan adalah debugger, emulator, library, dan dokumentasi. Semua jenis perangkat pintar mendukung aplikasi android yang dikembangkan studio. Dalam pembangunan aplikasi selular AR Wood Carving Art, Android SDK penting untuk pusat 3-Drawing dan membangun aplikasi yang mudah digunakan.

\subsection{Perangakt Keras}

Perangkat keras sangat penting untuk menjalankan program. Dalam pengembangan aplikasi selular AR Wood Carving Art, diperlukan komputer dengan sistem operasi yang mendukung penggunaan android. Komputer dengan sistem operasi Windows 10.1 yang mendukung prosesor Intel Inside dan RAM 8 GB diperlukan untuk pengerjaan gambar 3 Dimensi. Selain itu, webcam diperlukan untuk tujuan penandaan.

\subsection{Instrumen Penelitian}

Mengumpulkan informasi tentang persyaratan fungsional dasar sangat penting untuk membangun aplikasi yang memuaskan dan efektif. Dua alat instrumental yang digunakan dalam AR Wood Carving adalah kuesioner berbasis formulir google dan sesi wawancara semi-terstruktur. Kuesioner didasarkan pada pertanyaan tertutup untuk mengumpulkan informasi yang diperlukan. Kuesioner dimodifikasi dari Panessai [31].

Kuesioner bertujuan untuk memahami harapan dan kebutuhan pengguna dalam aplikasi. Kuesioner dilakukan di SMK Pasir Gudang (Johor) dan secara keseluruhan, 27 siswa menjawab kuesioner. Menjalankan metode daftar periksa membantu mengidentifikasi tugas yang terlewat dalam pengembangan dan mengevaluasi proses.

Selain itu, sesi wawancara dilakukan dengan pendekatan asinkron dengan guru yang bertugas. Sesi wawancara ini berlangsung selama satu minggu untuk mengumpulkan semua informasi penting untuk 
mengembangkan sistem.

\subsection{Mengembangkan aplikasi selular AR Word Carving Art}

Untuk merancang konten, pengembang menggunakan informasi penting yang dikumpulkan terkait dengan instruksional dan konten topik pada aplikasi selular AR Wood Carving Art. Pengembang menyusun dan menyiapkan storyboard dan antarmuka untuk aplikasi selular AR Wood Carving Art dalam pendidikan seni rupa khususnya pada subjek seni ukir kayu.

Selain itu, pengembang merancang bagan alur kerja aplikasi seluler yang melibatkan target gambar berbasis penanda dan menyiapkan model 3D gambar seni ukir kayu. Detail bagan alur yang digunakan dalam mengembangkan aplikasi selular AR Wood Carving Art ditunjukkan pada Gambar 3.

Gambar 3 menggambarkan bahwa pengembang memulai aplikasi dengan memilih topik yang sesuai pada Wood Carving Art, dalam pendidikan seni rupa khususnya pada subjek seni ukir kayu. Pengembang telah menentukan subtopik teknik kerajinan yaitu Ukiran layang, Ukiran Tebuk Timbul Bersilat, Ukiran Tebuk Timbul Tanpa Silat, Ukiran Tebuk Tembus Bersilat, dan Ukiran Tebuk Tanpa Tembus Silat.

Selain itu, pengembang merancang target gambar dengan menggunakan Canva dan mengubahnya menjadi Photoshop untuk mengubah format menjadi JPEG, dan objek 3 Dimensi dibuat melalui vektorizer menggunakan Inkscape dan dikonversi ke format file SVG. Kemudian gunakan Blender untuk membuat format file fbx 3 Dimensi dan menambahkan aset ke Unity.

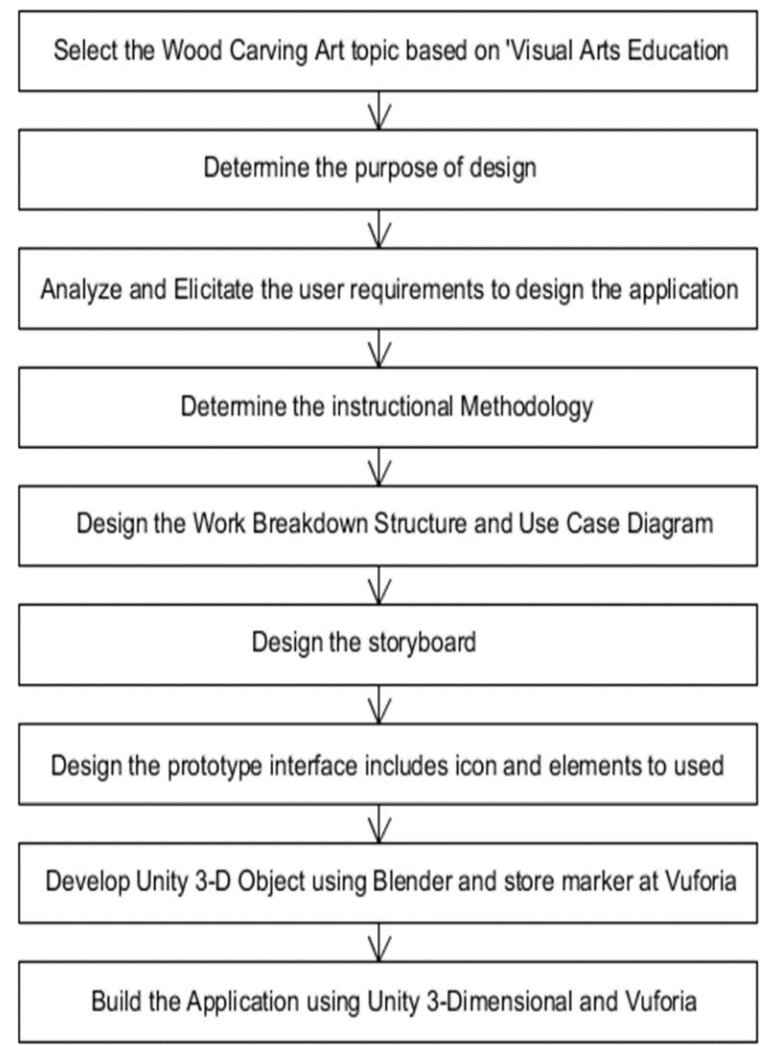

Gambar 3. Bagan alur untuk pengembangan aplikasi selular AR Wood Carving Art

\section{Hasil dan Analisis}

Sesi ini menunjukkan hasil dan analisis aplikasi selular AR Wood Carving Art. Aplikasi selular AR Wood Carving Art dievaluasi oleh 21 siswa-siswa yang sedang belajar ukiran kayu pada subjek seni di Sekolah XYZ Batam.

\subsection{Hasil}

Gambar 4 menunjukkan tampilan aplikasi selular AR Wood Carving Art. 


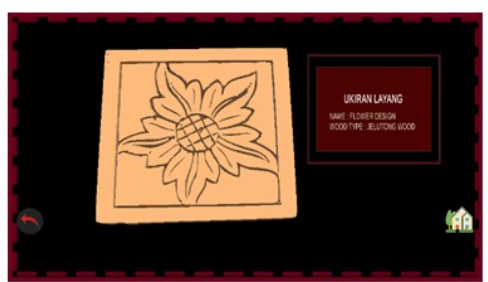

(a)

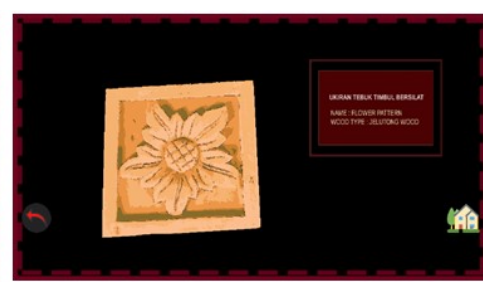

(b)

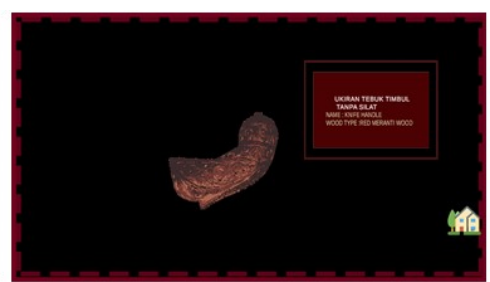

(c)

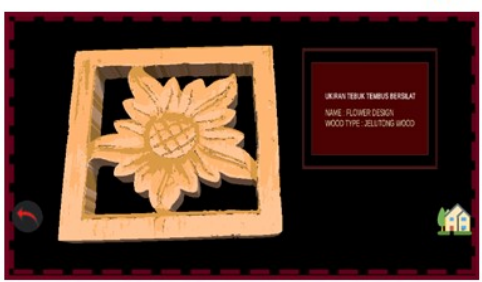

(d)

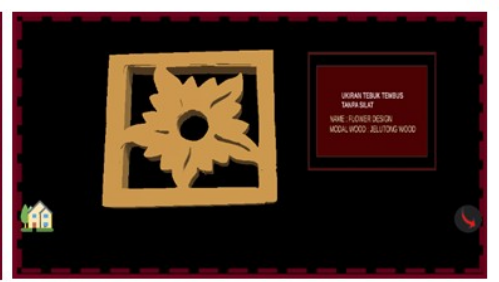

(e)

Gambar 4. Aplikasi seluler AR Wood Carving Art:

(a) Ukiran Layang,

(b) Ukiran Tebuk Timbul Bersilat,

(c) Ukiran Tebuk Timbul Tanpa Silat,

(d) Ukiran Tebuk Tembus Bersilat, dan

(e) Ukiran Tebuk Tembus Tanpa Silat.

Kuesioner yang disiapkan didasarkan pada usefulness untuk mengukur usability aplikasi selular AR Wood Carving Art. Usability adalah sebuah penanda yang menunjukkan sejauh mana Aplikasi seluler AR Wood Carving Art dapat digunakan sedangkan usefulness menunjukkan sejauh mana Aplikasi seluler AR Wood Carving Art dapat membantu meningkatkan kinerja dan prestasi belajar siswa. Hasil pengumpulan data ditampilkan dalam Tabel 1.

Tabel 1. Hasil Pengumpulan Data dari Kuesioner

\begin{tabular}{|c|c|c|c|c|c|c|c|}
\hline & & 1 & 2 & 3 & 4 & 5 & SUM \\
\hline \multicolumn{8}{|c|}{ USEFULNESS } \\
\hline Q-B1 & $\begin{array}{l}\text { Aplikasi AR Wood Craving Art membantu saya } \\
\text { menjadi lebih efektif }\end{array}$ & 0 & 0 & 0 & 2 & 19 & 21 \\
\hline Q-B2 & $\begin{array}{l}\text { Aplikasi AR Wood Craving Art membantu saya } \\
\text { menjadi lebih produktif. }\end{array}$ & 0 & 0 & 0 & 2 & 19 & 21 \\
\hline Q-B3 & Aplikasi Wood Craving Art AR berguna. & 0 & 0 & 0 & 2 & 19 & 21 \\
\hline Q-B4 & $\begin{array}{l}\text { Aplikasi Wood Craving Art AR memberi saya } \\
\text { gambaran tentang menjadi kreatif dan inovatif. }\end{array}$ & 0 & 0 & 0 & 2 & 19 & 21 \\
\hline Q-B5 & $\begin{array}{l}\text { Aplikasi AR Wood Craving Art membuat hal-hal } \\
\text { yang ingin saya capai lebih mudah untuk } \\
\text { diselesaikan. }\end{array}$ & 0 & 0 & 0 & 0 & 21 & 21 \\
\hline Q-B6 & $\begin{array}{l}\text { Aplikasi AR Wood Craving Art menghemat waktu } \\
\text { saya ketika saya menggunakannya. }\end{array}$ & 0 & 0 & 0 & 2 & 19 & 21 \\
\hline Q-B7 & $\begin{array}{l}\text { Aplikasi AR Wood Craving Art memenuhi } \\
\text { kebutuhan saya. }\end{array}$ & 0 & 0 & 0 & 2 & 19 & 21 \\
\hline Q-B8 & $\begin{array}{l}\text { Aplikasi AR Wood Craving Art melakukan semua } \\
\text { yang saya harapkan. }\end{array}$ & 0 & 0 & 0 & 0 & 21 & 21 \\
\hline
\end{tabular}




\subsection{Analisis}

Fase ini membantu mengumpulkan elemen yang perlu ditambahkan di masa depan untuk kinerja yang lebih baik. Kuesioner tersebut terdiri dari enam pertanyaan yang telah dievaluasi oleh responden. Gambar 5 menunjukkan umpan balik responden terhadap kemudahan penggunaan aplikasi selular AR Wood Carving Art.

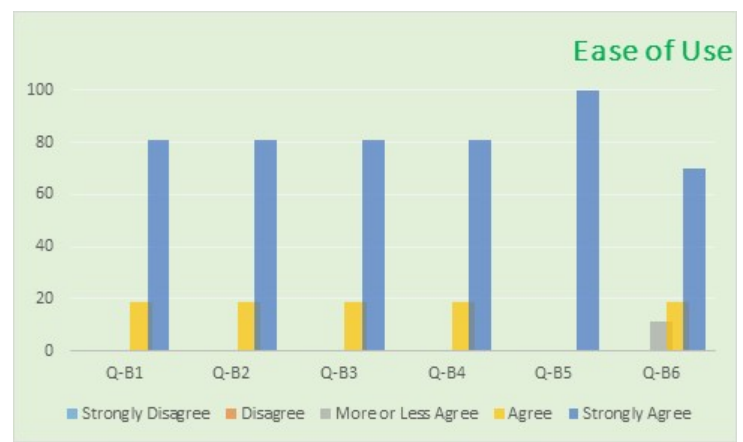

Gambar 5. Tanggapan Responden: Kemudahan Penggunaan

Pertanyaan Q-B1 adalah tentang aplikasi seluler AR Wood Carving Art mudah digunakan, di mana $80 \%$ responden sangat setuju, dan 20\% responden setuju. Sementara Pertanyaan Q-B2 mengenai pernyataan Aplikasi Ukiran Kayu terstruktur dengan baik, di mana $80 \%$ responden sangat setuju, dan $20 \%$ responden setuju. Pertanyaan Q-B3 terkait dengan pernyataan bahwa Aplikasi Ukiran Kayu fleksibel dan mudah, di mana $80 \%$ responden sangat setuju, dan $20 \%$ responden setuju dengan titik ini. Pertanyaan Q-B4 adalah untuk pernyataan bahwa pengguna dapat menggunakan aplikasi tanpa panduan pengguna, di mana $80 \%$ responden sangat setuju, dan $20 \%$ responden setuju dengan titik ini. Pertanyaan Q-B5 adalah tentang pengguna yang tidak melihat inkonsistensi karena pengguna menggunakan aplikasi seluler AR Wood Carving Art yang 100\% responden sangat setuju.

Pertanyaan Q-B6 adalah tentang pernyataan bahwa pengguna dapat menggunakan aplikasi AR Woodcarving Art dengan sukses setiap saat. Dalam pertanyaan ini, 70\% responden sangat setuju, 19\% responden setuju, dan $11 \%$ responden kurang lebih setuju. Rata-rata, $80 \%$ responden bereaksi keras terhadap pertanyaan di bagian kemudahan penggunaan. Responden berpikir bahwa aplikasi AR Wood Craving Art mudah digunakan, terstruktur dengan baik, fleksibel, dan mudah. 100\% responden sangat setuju bahwa pengguna tidak melihat inkonsistensi apa pun dalam aplikasi seluler AR Wood Carving Art. Yang perlu diperhatikan dan ditingkatkan adalah pernyataan bahwa pengguna dapat menggunakan aplikasi seluler AR Wood Carving Art dengan sukses setiap saat. Berdasarkan wawancara yang dilakukan, kegagalan penggunaan aplikasi mobile AR Wood Carving Art adalah perangkat pengguna terkadang tidak dapat membaca penanda yang disediakan.

\section{Kesimpulan}

Penelitian ini memperluas pemahaman tentang bagaimana teknologi kreatif dan inovatif telah terintegrasi dengan pendidikan dan membantu memfasilitasi proses pembelajaran. Keberadaan aplikasi selular AR Wood Carving Art dapat memenuhi kebutuhan teknologi modern dan informasi yang akurat serta keterampilan yang berguna dan pemikiran kritis. Pengembangan aplikasi interaktif juga sejalan dengan Elemen Lintas Kurikulum melalui penerapan unsur sains dan teknologi serta kreativitas dan inovasi. Berdasarkan evaluasi efektivitas, disimpulkan bahwa siswa dapat lebih terlibat aktif dalam pembelajaran mandiri melalui pendekatan inovatif yang akan membuat siswa berpikir kritis. Siswa dapat memahami dengan baik contoh lima teknik ukiran 3-Dimensi dalam aplikasi seluler AR Wood Carving Art. Berdasarkan masukan responden, upaya perlu dilakukan untuk mengatasi kegagalan perangkat pengguna dalam membaca marker yang disediakan. Konten dalam kanvas gambar perlu ditingkatkan agar lebih akurat untuk mengatasi kegagalan perangkat pengguna untuk membaca penanda yang disediakan. 


\section{Daftar Pustaka}

[1] T. Khan, K. Johnston, dan J. Ophoff, "Dampak dari Aplikasi Augmented Reality tentang Motivasi Belajar Siswa, $A H C I$, vol. 19, no. 1, pp. 1-14, 2019.

[2] H. Köse, dan N. Güner-Yildiz, "Augmented Reality sebagai bahan pembelajaran dalam pendidikan berkebutuhan khusus," EIT, vol. 26, no. 1, pp. 1921-1936, 2021.

[3] A. Theodoropoulos, dan G. Lepouras, "Augmented Reality and programming education: A systematic review," IJCCI, vol. 10, 2021. doi: 10.1016/j.ijcci.2021.100335.

[4] W. A. N. Wan Idris, H. Halim, dan H. Hassan, "GENIUS KIDS: Learn to Count through Games", International Journal of Multimedia and Recent Innovation, vol. 1, no. 1, pp. 1-17, 2019. doi: 10.36079/lamintang.ijmari-0101.71

[5] H. Halim, W. A. N. Wan Idris, H. Hassan, and I. Y. Panessai, "Learning Logic Gate through 7Gates", International Journal of Multimedia and Recent Innovation, vol. 2, no. 1, pp. 1-10, 2020. doi: 10.36079/lamintang.ijmari-0201.70

[6] M. A. Ishak, M. R, Kosnan, and N. F. Zakaria, "Build IoT through Virtual Reality", International Journal of Multimedia and Recent Innovation, vol. 2, no. 1, pp. 11-25, 2020. doi: 10.36079/lamintang.ijmari-0201.80

[7] A. Z. Zakaria, H. Hassan, H. Halim, W. A. N. Wan Idris, M. A. Abdullah Zawawi, and N. F. Mansor, "Learning Mathematics: One Minute", International Journal of Multimedia and Recent Innovation, vol. 2, no. 2, pp. 76-86, 2020. doi: 10.36079/lamintang.ijmari-0202.130

[8] D. Roopa, R. Prabha, and G. A. Senthil, "Revolutionizing education system with interactive augmented reality for quality education," Materials Today: Proceedings. 2021. doi: 10.1016/j.matpr.2021.02.294.

[9] H. J. Kim \& S. Lee, "Examining the Role of Engaging in Research Activities with Digital Technologies for Graduate Students' Success," IJETL, vol. 16, no. 4, pp. 212-227, 2021.

[10] A. Lumbe, R. V. Mangizvo, and C. Mushaka, "Feasibility of Total Migration to Online Learning in Zimbabwe Open University: The Case of Gokwe North District Centre," IJREHC, vol. 2, no. 2, pp. 85-99, 2021.

[11] S. Shorbagi, N. Sulaiman, A. Hasswan, M. Kaouas, M. M. Al-Dijani, R. A. El-hussein, M. T. Daghistani, S. Nugud, and S. Y. Guraya, Evaluating the feasibility and effectiveness of e-OSCE in the COVID- 19 Era," Researchsquare, pp. 1-21. 10.21203/rs.3.rs-506145/v1, 2021.

[12] J. B. Barhorst, G. McLean, E. Shah, and R. Mack, "Blending the real world and the virtual world: Exploring the role of flow in augmented reality experiences," Journal of Business Research, vol. 122, pp. 423-436, 10.1016/j.jbusres.2020.08.041, 2021.

[13] P. A. Rauschnabel, "Augmented reality is eating the real-world! The substitution of physical products by holograms," International Journal of Information, vol. 57, pp. 268-4012. 2021. doi: $10.1016 /$ j.ijinfomgt.2020.

[14] N. A. N. Ibharim, S. Z. Ramli, S. A. Zahari, N. A. A. Edyanto, and M. A. Abdullah Zawawi, "Learning History Using Augmented Reality," International Journal of Multimedia and Recent Innovation, vol. 3, no. 1, pp. 1-10, 2021. doi: lamintang.ijmari-0301.199

[15] B. Liu, and J. Tanaka, "Virtual Marker Technique to Enhance User Interactions in a MarkerBased AR System," Applied Sciences, 10.3390/app11104379, 2021.

[16] I. A. A. Putra, and I. G. N. A. C. Putra, "Development of Augmented Reality Application for Canang Education Using Marker-Based Tracking Method," Jurnal Elektronik Ilmu Komputer Udayana, vol. 9, no. 3, pp. 365-274, 2021.

[17] N. Golse, P. Petit, M. Lewin, E. Vibert, and S. Cotin, "Augmented Reality during Open Liver Surgery Using a Markerless Non-rigid Registration System," Journal of Gastrointestinal Surgery, vol. 25, pp. 662-671, 2020

[18] A. Elsharkawy, K. Naheem, D. Koo, and M. S. Kim, “A UWB-Driven Self-Actuated Projector Platform for Interactive Augmented Reality Applications," Applied Sciences, vol. 11, no. 6, doi.org/10.3390/app11062871, 2021.

[19] A. Gomes, K. Fernandes, and D. Wang, "Surface Prediction for Spatial Augmented Reality Applications," Virtual Reality, 2021. doi: 10.1007/s10055-020-00490-2.

[20] R. K. Gupta, Augmented Reality Based Collaborative Product Enhancement. Springer, Singapore, 2021.

[21] R. Romli, M. A. Aznan, L. Z. Xian, A. A. Bakhoruddin, F. N. H. Mohd Wazir, and A. R. S. Gurdial Singh, AR@UNIMAP: A Development of Interactive Map Using Augmented Reality," Journal of Physics: Conference Series, vol. 1755, 2020. 
[22] S. N. S. Abu Samah, "The Efficacy of Augmented Reality on Student Achievement and Perception among Teluk Intan Community College Student in Learning 3D Animation," International Journal of Multimedia and Recent Innovation, vol. 2, no. 2, pp. 87-95, 2020. doi: 10.36079/lamintang.ijmari-0202.131

[23] N. A.Atikah, S. Z. Ramli, N. A. A. Ibharim, S. A. Zahari, and M. A. A. Zawawi, "Learn Idioms Using Augmented Reality," International Journal of Multimedia and Recent Innovation, vol. 3, no. 1, pp. 11-16, 2021. doi: 10.36079/lamintang.ijmari-0301.199

[24] Kementerian Pendidikan Malaysia. Sukatan Pelajaran Kurikulum Bersepadu Sekolah Menengah: Pendidikan Seni Visual. Kuala Lumpur: Pusat Pembangungan Kurikulum KPM, 2020.

[25] R. M. Rabori, B. Bagherian, and M. Nematollahi, "Simulation-based mastery improves nursing skills in BSc nursing students: a quasi-experimental study," BMC Nursing, vol. 20, no. 10, 2021.

[26] N. I. M. K. Daud, E. Arbi, and M. Faizal, "Pengaplikasian ukiran kayu melayu dalam seni bina di Malaysia," Journal of Design and Built Environment, vol. no. 11, pp. 1-14, 2012.

[27] G. Chilton, N. Gerber, A. Bechtel, T. Councill, M. Dreyer, and E. Yingling, "The Art of Positive Emotions: Expressing Positive Emotions within the Intersubjective Art Making Process," Canadian Art Therapy Association Journal, vol. 28, no. 1, 2015. doi: 10.1080/08322473. 2015.1100580.

[28] D. D. Pradipta, Madlazim, E. Hariyono, "The Effectiveness of Science Learning Tools Based on Education Sustainable Development (ESD) to Improve Problem-Solving Skills," International Journal of Recent Education Research, vol. 2, no. 3, 2021. doi: doi.org/10.46245/ijorer. v2i3.113.

[29] H. N. Fatiyah, Riandi, and R. Solihat, "Development of learning tools education for sustainable development (ESD) integrated problem-solving for high school," Journal of ICMScE, vol. 1806, 2020.

[30] N. H. Rahani, A. A. Bilong, M. R. Mat Suruji, and I. Y. Panessai, "Learning Logic Gates Using Augmented Reality," International Journal of Multimedia and Recent Innovation, vol. 2, no. 1, pp. 26-44, 2020. doi: 10.36079/lamintang.jjmari-0201.81

[31] I. Y. Panessai, N. Iksan, S. A. Zahari, A. S. Abdulbaqi, M. M. Lakulu, M. R. Husin, H. Ahmad, H. AbdArif and Pratiwi, Learning Internet of Things by using Augmented Reality, in ICVARS 2021: 2021 the 5th International Conference on Virtual and Augmented Reality Simulations. Australia. March 20-22, 2021, Melbourne, VIC, Australia, 2021.

[32] S. F. Sezali, A. M. Radzuan, N. I. MohdShabudin, and R. A. Afendi, "POCKET MALAYSIA: Learning About States in Malaysia Using Augmented Reality," International Journal of Multimedia and Recent Innovation, vol. 2, no. 1, pp. 45-59, 2020. doi: 10.36079/lamintang.ijmari-0201.82.

[33] Z. Zainal Abidin, and M. A. Abdullah Zawawi, "OOP-AR: Learn Object Oriented Programming Using Augmented Reality", International Journal of Multimedia and Recent Innovation, vol. 2, no. 1, pp. 60-75, 2020. doi: 10.36079/lamintang.ijmari-0201.83. 